\title{
Role of five small nucleotide polymorphisms in the VEGF gene on the susceptibility to osteosarcoma and overall survival of patients
}

\author{
JIAN-QIANG LIU ${ }^{1 *}$, XIA BAI $^{1 *}$, DE-CHEN DUAN ${ }^{1}$ and AI-XIA DOU ${ }^{2}$ \\ ${ }^{1}$ Department of Orthopaedics, Jinan No. 4 Hospital; ${ }^{2}$ Department of Hematology and Oncology, \\ The Second Hospital of Shandong University, Jinan, Shandong, P.R. China
}

Received June 21, 2014; Accepted March 13, 2015

DOI: 10.3892/ol.2015.3396

\begin{abstract}
The present study aimed to investigate the association between five common small nucleotide polymorphisms (SNPs) in the VEGF gene and the risk of osteosarcoma. An additional aim was to investigate the role of these five SNPs on the prognosis of osteosarcoma. A total of 186 patients with osteosarcoma and 186 age- and sex-matched healthy controls were enrolled into the present study. A polymerase chain reaction-restriction fragment length polymorphism assay was conducted to determine the incidence of the VEGF-2578 C/A, -1156 G/A, +1612 G/A, +936 C/T and -634 G/C polymorphisms. Conditional logistic regression analyses revealed that individuals carrying the -634 GG genotype possessed a significantly increased risk of osteosarcoma, with an adjusted odds ratio [(95\% confidence interval (CI)] of 2.00 (1.07-3.75). In the Cox proportional hazards model, subsequent to adjusting for potential confounding factors, patients with osteosarcoma carrying the $-634 \mathrm{GG}$ genotype were found to demonstrate a shorter overall survival time (hazard ratio, 3.10; 95\% CI, 1.17-8.38). The VEGF-634 G/C polymorphism may therefore be used as a genetic marker for the prediction of the risk and clinical outcome of osteosarcoma.
\end{abstract}

\section{Introduction}

Osteosarcoma is derived from mesenchymal tissues and often occurs in the distal femur, proximal tibia and humeral metaphysis. Osteosarcoma is one of the most common malignant tumors in children and adolescents. It is estimated that the annual incidence of osteosarcoma is 4-5 cases per 1,000,000 individuals worldwide, and osteosarcoma is a leading cause

Correspondence to: Dr Ai-Xia Dou, Department of Hematology and Oncology, The Second Hospital of Shandong University, 247 North Park Main, Jinan, Shandong 250000, P.R. China

E-mail: douaixia2@163.com

*Contributed equally

Key words: single nucleotide polymorphism, vascular endothelial growth factor, susceptibility, clinical outcome, osteosarcoma of cancer-associated mortalities in children and young adults (1-3).

The development of osteosarcoma is a complex, multistep and multifactorial process in which numerous factors are implicated (4-6). Several studies have been performed to investigate cancer stem cells and the potential of these cells to cause tumors $(7,8)$. The concept that genetic factors are involved in the development of osteosarcoma has led to numerous studies investigating genetic determinants for osteosarcoma in the past decade (10-13).

Vascular endothelial growth factor (VEGF) is one of the most potent endothelial cell mitogens, and performs an important role in angiogenesis $(14,15)$. The VEGF gene, which consists of eight exons that undergo alternative splicing to form a family of proteins, is located at chromosome $6 \mathrm{p} 21.3$. It is well known that the VEGF gene results in several alternatively spliced isoforms, and the regulation of VEGF expression can reveal the difference between normal and tumor tissues. It is estimated that there are $>30$ types of single nucleotide polymorphism (SNP) in the VEGF gene (16), and several SNPs in the VEGF gene have been reported to affect the expression of the VEGF gene (16). Among these SNPs, five common SNPs in the VEGF gene, consisting of $-2578 \mathrm{C} / \mathrm{A}$, $-1156 \mathrm{G} / \mathrm{A},+1612 \mathrm{G} / \mathrm{A},+936 \mathrm{C} / \mathrm{T}$ and $-634 \mathrm{G} / \mathrm{C}$, are reported to be associated with VEGF protein synthesis (17). The $-2578 \mathrm{C} / \mathrm{A}$ and $-1156 \mathrm{G} / \mathrm{A}$ SNPs are located at the VEGF promoter region, and the $+1612 \mathrm{G} / \mathrm{A},+936 \mathrm{C} / \mathrm{T}$ and $-634 \mathrm{G} / \mathrm{C}$ SNPs are located at the 3'-untranslated region. Previous studies have reported that VEGF polymorphisms are associated with the risk of several cancers, including breast, prostate, renal cell and head and neck cancers (18-20). However, studies reporting the association between the five SNPs in the VEGF gene and susceptibility to osteosarcoma are limited $(21,22)$. Therefore, the aim of the present study was to investigate the association between five common SNPs in VEGF and the risk of osteosarcoma, in addition to the role of the SNPs in the prognosis of osteosarcoma.

\section{Materials and methods}

Participants. A hospital-based case-control study was performed in the present study. A total of 186 patients with osteosarcoma and 186 age- and sex-matched healthy controls were enrolled into the present study from the No. 4 Hospital of Jinan (Jinan, Shandong, China) between January 2008 and 
December 2010. The patients with osteosarcoma were newly-diagnosed and the diagnosis was histopathologically confirmed by two independent pathologists. The clinical and pathological information of the patients was extracted,including Enneking stage (consisting of stages I, II and III) (23), tumor location in the extremities or other locations, histological type (consisting of osteoblastic, chondroblastic, fibroblastic and mixed types), presence of tumor metastasis, and family history of cancer. The control subjects met the following criteria: No medical history of any tumor or cancer; no family history of osteosarcoma or other cancers in first-degree relatives; and matched with the same nationality as the patients. The present study was approved by the ethics committee of Jinan No. 4 Hospital, and each individual provided written informed consent for participation in the present study.

The demographic data and medical and family histories were obtained by a face to face interview using a self-designed questionnaire. The face to face interview was completed by trained nurses or doctors.

All the patients were followed up until 30th December 2012 , with a median follow-up time of 35.6 months (range, 2-60 months). All patients were followed up by telephone every four weeks until mortality or the end of the study. The overall survival (OS) time was calculated from the date of enrolling in this study to the date of mortality or last clinical follow-up.

Blood samples and genotyping. Each patient provided $5 \mathrm{ml}$ of peripheral blood, which was maintained at $-70^{\circ} \mathrm{C}$ prior to use, and EDTA with $0.5 \mathrm{mg} / \mathrm{ml}$ was used as an anticoagulant. Genomic DNA was isolated using the TIANamp blood DNA kit (Tiangen, Beijing, China) according to the manufacturer's instructions. Probes and primers for VEGF-2578C/A (rs699947), -1156G/A (rs1570360), +1612G/A (rs10434), +936C/T (rs3025039) and -634G/C (rs2010963) were designed using Primer 5.0 software (PREMIER Biosoft, Palo Alto, CA, USA). Polymerase chain reaction restriction fragment length polymorphism (PCR-RFLP) assay was conducted to determine the frequency of the VEGF-2578C/A, -1156G/A, $+1612 \mathrm{G} / \mathrm{A},+936 \mathrm{C} / \mathrm{T}$ and $-634 \mathrm{G} / \mathrm{C}$ polymorphisms. The PCR reaction was conducted using a Perkin-Elmer 9700 thermocycler (Perkin-Elmer, Waltham, MA, USA) with an initial denaturation step of $5 \mathrm{~min}$ at $94^{\circ} \mathrm{C}$, followed by 35 cycles of denaturing at $94^{\circ} \mathrm{C}$ for $45 \mathrm{sec}$, annealing at $62^{\circ} \mathrm{C}$ for $60 \mathrm{sec}$ and extending at $72^{\circ} \mathrm{C}$ for $60 \mathrm{sec}$, and a final extension was performed at $72^{\circ} \mathrm{C}$ for $10 \mathrm{~min}$. The PCR products were visualized in $1.0 \%$ agarose gel electrophoresis and stained using ethidium bromide staining and ultraviolet light. In order to perform quality control, a randomly chosen subgroup of $10 \%$ of osteosarcoma cases was selected to repeat the genotyping, and the reproducibility was $100 \%$.

Statistical analysis. Continuous variables were expressed as the mean \pm standard deviation and were analyzed using a Student's $t$-test. Categorical variables were expressed as the frequency and percentage of study participants, and were analyzed using the $\chi^{2}$-test. The Hardy-Weinberg equilibriums of the VEGF $-2578 \mathrm{C} / \mathrm{A},-1156 \mathrm{G} / \mathrm{A},+1612 \mathrm{G} / \mathrm{A},+936 \mathrm{C} / \mathrm{T}$ and $-634 \mathrm{G} / \mathrm{C}$ genotype frequencies in the control subjects were analyzed using the $\chi^{2}$-test. The differences in genotype frequencies between the osteosarcoma and control groups were assessed using the $\chi^{2}$-test, and the results were assessed in terms of odds ratio (OR) and confidence intervals (CI). The hazard ratio (HR) and 95\% CI were calculated by Cox proportional hazards models, and used to evaluate the effect of the VEGF $-2578 \mathrm{C} / \mathrm{A},-1156 \mathrm{G} / \mathrm{A},+1612 \mathrm{G} / \mathrm{A},+936 \mathrm{C} / \mathrm{T}$ and $-634 \mathrm{G} / \mathrm{C}$ polymorphisms on the OS time of patients with osteosarcoma. The Kaplan-Meier method was used to plot the OS curves. $\mathrm{P}<0.05$ was considered to indicate a statistically significant difference, and all tests were two-tailed. All statistical analyses were performed using SPSS statistical software, version 16.0 (SPSS, Inc., Chicago, IL, USA) for Windows.

\section{Results}

The characteristics of patients with osteosarcoma and control individuals are shown in Table I. No significant differences were identified between the gender and age at enrollment of patients and control individuals in the present study. The mean age of patients with osteosarcoma was $18.5 \pm 10.3$ years and the mean age of control individuals was $19.2 \pm 11.8$ years. Of the 186 patients with osteosarcoma, 125 patients $(72.58 \%)$ possessed tumors of the long tubular bones and $51(27.42 \%)$ possessed tumors of the axial skeleton. In total, metastasis was identified in $43(23.12 \%)$ patients at the time of enrollment in the present study.

The frequency of the VEGF-2578C/A, $-1156 \mathrm{G} / \mathrm{A},+1612 \mathrm{G} / \mathrm{A}$, $+936 \mathrm{C} / \mathrm{T}$ and $-634 \mathrm{G} / \mathrm{C}$ genotypes in the osteosarcoma and control groups are shown in Table II. The genotype frequencies of the VEGF-2578C/A, -1156G/A, +1612G/A, +936C/T and $-634 \mathrm{G} / \mathrm{C}$ SNPs were found to be in line with the Hardy-Weinberg equilibrium. Conditional logistic regression analysis revealed that subjects carrying the $-634 \mathrm{GG}$ genotype possessed a significantly increased risk of osteosarcoma, with an adjusted OR (95\% CI) of 2.00 (1.07-3.75). However, no significant association was identified between the VEGF-2578C/A, -1156G/A, $+1612 \mathrm{G} / \mathrm{A}$ and $+936 \mathrm{C} / \mathrm{T}$ SNPs and the risk of osteosarcoma.

In addition, an analysis was performed to assess the association between the five SNPs in the VEGF gene and the OS time of patients with osteosarcoma (Table III). During the follow-up period, 63 patients $(33.87 \%)$ succumbed to osteosarcoma during the follow-up period. In the Cox proportional hazards model, subsequent to adjusting for potential confounding factors, patients with osteosarcoma carrying the $-634 \mathrm{GG}$ genotype demonstrated a shorter OS time (HR, $3.10 ; 95 \% \mathrm{CI}, 1.17-8.38)$, and the $-634 \mathrm{G} / \mathrm{C}$ polymorphism was therefore an independent prognostic factor for osteosarcoma (Fig. 1). However, no significant association was observed between the $-2578 \mathrm{C} / \mathrm{A},-1156 \mathrm{G} / \mathrm{A},+1612 \mathrm{G} / \mathrm{A}$ and $+936 \mathrm{C} / \mathrm{T}$ polymorphisms and the OS time of patients with osteosarcoma.

\section{Discussion}

VEGF, a growth factor that regulates angiogenesis, is localized on chromosome 6p21.3. In total, $>30$ SNPs have been identified in this gene. VEGF is regarded as the most potent stimulatory cytokine for the initiation of tumor angiogenesis and is also an important factor for the development, metastasis, survival and spread of the tumor (24). Previous studies have reported that the expression of VEGF demonstrates an 
Table I. Characteristics of the patients with osteosarcoma and the control subjects.

\begin{tabular}{|c|c|c|c|c|}
\hline Characteristics & Osteosarcoma group & Control group & $t$ or $\chi^{2}$ test & P-value \\
\hline Total, n (\%) & $186(100.00)$ & $186(100.00)$ & & \\
\hline Age, years & & & 0.03 & 0.87 \\
\hline Mean age & $18.5 \pm 10.3$ & $19.2 \pm 11.8)$ & & \\
\hline$<20$ & $119(63.98)$ & $127(68.28)$ & & \\
\hline$>20$ & $67(36.02)$ & $69(37.10)$ & & \\
\hline Gender, n (\%) & & & 0.00 & 1.00 \\
\hline Male & $114(61.29)$ & $114(61.29)$ & & \\
\hline Female & $72(38.71)$ & $72(38.71)$ & & \\
\hline \multicolumn{5}{|l|}{ Tumor location, $\mathrm{n}(\%)$} \\
\hline Long tubular bones & $135(72.58)$ & & & \\
\hline Axial skeleton & $51(27.42)$ & & & \\
\hline \multicolumn{5}{|l|}{ Metastasis, n (\%) } \\
\hline No & $43(23.12)$ & & & \\
\hline Yes & $143(76.88)$ & & & \\
\hline
\end{tabular}

Table II. Genotype distribution of five SNPs in VEGF gene between osteosarcoma cases and controls.

\begin{tabular}{|c|c|c|c|c|c|}
\hline SNPs & Genotype & Osteosarcoma, n (\%) & Control group, n (\%) & OR $(95 \% \mathrm{CI})^{\mathrm{a}}$ & P-value \\
\hline \multirow[t]{3}{*}{$-2578 \mathrm{C} / \mathrm{A}$} & $\mathrm{CC}$ & $79(42.47)$ & 87 (46.77) & 1.0 (Ref.) & - \\
\hline & $\mathrm{CA}$ & $75(40.32)$ & $73(39.25)$ & $1.13(0.62-1.81)$ & 0.59 \\
\hline & AA & $32(17.20)$ & $26(13.98)$ & $1.36(0.73-2.59)$ & 0.32 \\
\hline \multirow[t]{3}{*}{$-1156 \mathrm{G} / \mathrm{A}$} & AA & $107(57.53)$ & $116(62.37)$ & 1.0 (Ref.) & - \\
\hline & $\mathrm{AG}$ & $53(28.49)$ & $49(26.34)$ & $1.17(0.64-1.93)$ & 0.51 \\
\hline & GG & $27(14.52)$ & $21(11.29)$ & $1.39(0.68-2.76)$ & 0.30 \\
\hline \multirow[t]{3}{*}{$+1612 \mathrm{G} / \mathrm{A}$} & GG & $75(40.32)$ & $84(45.16)$ & 1.0 (Ref.) & - \\
\hline & GA & $86(46.24)$ & $83(44.62)$ & $1.16(0.74-1.83)$ & 0.50 \\
\hline & AA & $25(13.44)$ & $19(10.22)$ & $1.47(0.71-3.07)$ & 0.25 \\
\hline \multirow[t]{3}{*}{$+936 \mathrm{C} / \mathrm{T}$} & $\mathrm{CC}$ & $125(67.20)$ & $134(72.04)$ & 1.0 (Ref.) & - \\
\hline & $\mathrm{CT}$ & $46(24.73)$ & $42(22.58)$ & $1.17(0.66-1.96)$ & 0.52 \\
\hline & $\mathrm{TT}$ & $16(8.60)$ & $10(5.38)$ & $1.71(0.71-4.39)$ & 0.20 \\
\hline \multirow[t]{3}{*}{$-634 \mathrm{G} / \mathrm{C}$} & $\mathrm{CC}$ & $50(26.88)$ & $69(37.10)$ & 1.0 (Ref.) & - \\
\hline & $\mathrm{CG}$ & $91(48.92)$ & $86(46.24)$ & $1.46(0.89-2.40)$ & 0.11 \\
\hline & GG & 45 (24.19) & $31(16.67)$ & $2.00(1.07-3.75)$ & 0.02 \\
\hline
\end{tabular}

${ }^{a}$ Adjusted for sex and age. SNPs, single nucleotide polymorphisms; OR, odds ratio; CI, confidence interval; Ref., reference genotype (wild type).

effect on the development and prognosis of several types of cancer (18-20,25). The VEGF-2578C/A, -1156G/A, +1612G/A, $+936 \mathrm{C} / \mathrm{T}$ and $-634 \mathrm{G} / \mathrm{C}$ SNPs have been previously identified, and all the polymorphisms were found to be located at the promoter region of VEGF. The five SNPs perform a role in the alteration of the transcription of the VEGF gene and also affect the expression of the VEGF gene. Several previous clinical studies have revealed that the five SNPs are associated with the development and prognosis of cancers $(18-20,25)$. In the present study, it was found that subjects carrying the -634GG genotype possessed a significantly increased risk of osteosarcoma, and this genotype was also associated with a shorter OS time in patients with osteosarcoma. The present study suggested that the $-634 \mathrm{G} / \mathrm{C}$ polymorphism may be an independent factor for the development and prognosis of osteosarcoma.

The exact mechanism of the VEGF gene polymorphisms on the susceptibility and clinical outcome of osteosarcoma remains unknown. It is well known that angiogenesis is an important factor for the development and prognosis of tumors, VEGF expression regulates angiogenesis, and therefore VEGF may have been involved in the promotion of endothelial cell proliferation and regulation of the extracellular matrix in the blood vessels $(26,27)$. The present study identified that the 
Table III. Role of five SNPs in VEGF gene in the overall survival of osteosarcoma cases.

\begin{tabular}{|c|c|c|c|c|c|c|}
\hline SNPs & Genotype & $\begin{array}{l}\text { Osteosarcoma } \\
\text { group, n }(\%)\end{array}$ & Mortalities, n (\%) & $\begin{array}{c}\text { Five-year } \\
\text { survival rate, \% }\end{array}$ & $\operatorname{HR}(95 \% \mathrm{CI})^{\mathrm{a}}$ & P-value \\
\hline \multirow[t]{3}{*}{$-2578 \mathrm{C} / \mathrm{A}$} & $\mathrm{CC}$ & 79 (42.47) & $30(47.62)$ & 87.10 & 1.0 (Ref.) & - \\
\hline & CA & $75(40.32)$ & $24(38.10)$ & 85.48 & $1.29(0.62-2.67)$ & 0.46 \\
\hline & $\mathrm{AA}$ & $32(17.20)$ & $9(14.29)$ & 93.55 & $1.38(0.52-3.51)$ & 0.47 \\
\hline \multirow[t]{3}{*}{$-1156 \mathrm{G} / \mathrm{A}$} & AA & $107(57.53)$ & $39(61.90)$ & 81.72 & 1.0 (Ref.) & - \\
\hline & $\mathrm{AG}$ & $53(28.49)$ & $17(26.98)$ & 89.78 & $1.20(0.56-2.53)$ & 0.61 \\
\hline & GG & $27(14.52)$ & 7 (11.11) & 94.09 & $1.48(0.55-3.81)$ & 0.38 \\
\hline \multirow[t]{3}{*}{$+1612 \mathrm{G} / \mathrm{A}$} & GG & $75(40.32)$ & $29(46.03)$ & 87.63 & 1.0 (Ref.) & - \\
\hline & GA & $86(46.24)$ & $28(44.44)$ & 83.87 & $1.21(0.59-2.48)$ & 0.57 \\
\hline & AA & $25(13.44)$ & $6(9.52)$ & 94.62 & $1.51(0.52-4.22)$ & 0.39 \\
\hline \multirow[t]{3}{*}{$+936 \mathrm{C} / \mathrm{T}$} & $\mathrm{CC}$ & $125(67.20)$ & $45(71.43)$ & 77.96 & 1.0 (Ref.) & - \\
\hline & $\mathrm{CT}$ & $46(24.73)$ & $14(22.22)$ & 90.86 & $1.20(0.55-2.56)$ & 0.61 \\
\hline & $\mathrm{TT}$ & $16(8.60)$ & $4(6.35)$ & 96.24 & $1.59(0.46-5.18)$ & 0.38 \\
\hline \multirow[t]{3}{*}{$-634 \mathrm{G} / \mathrm{C}$} & $\mathrm{CC}$ & $50(26.88)$ & $11(17.46)$ & 78.00 & 1.0 (Ref.) & - \\
\hline & $\mathrm{CG}$ & $91(48.92)$ & $31(49.21)$ & 65.93 & $1.83(0.78-4.51)$ & 0.13 \\
\hline & GG & 45 (24.19) & $21(33.33)$ & 53.33 & $3.10(1.17-8.38)$ & 0.01 \\
\hline
\end{tabular}

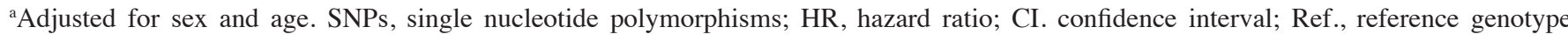
(wild type).

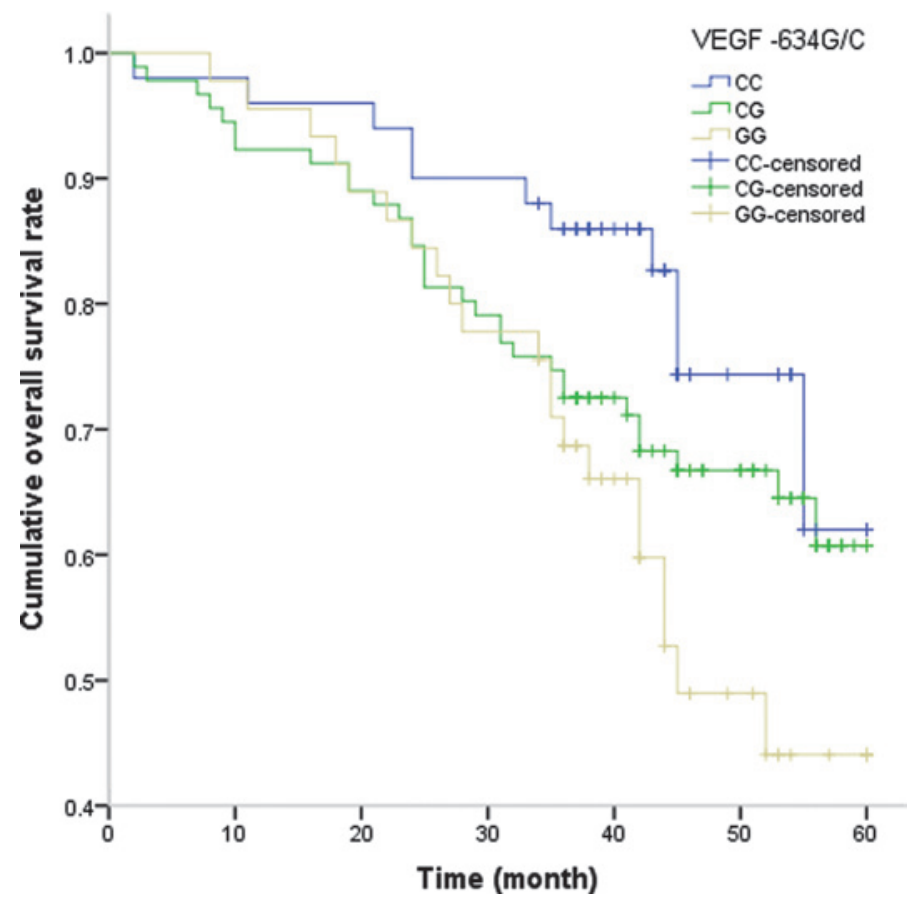

Figure 1. Kaplan-Meier analysis for the overall survival of individuals with the VEGF-634G/C polymorphism.

-634G/C polymorphism affects the development and prognosis of osteosarcoma. The VEGF-634G/C polymorphism is located in the 5'- and 3'-UTR of VEGF, and this SNP has been reported to influence the protein translation efficiency, circulating plasma concentrations and expression of VEGF in tumor tissues (28-30). Numerous studies have reported that the VEGF-634G/C polymorphism is associated with several types of cancers, including gastric, colorectal, lung and breast cancers (30-33). Liu et al (30) reported that the VEGF-634GC+CC genotype was associated with an increased risk of gastric cancer. The present study is consistent with these results. However, Zhao et al (31) and Deng et al (32) revealed that the VEGF-634CC genotype decreased the risk of colorectal and lung cancers. Yao et al (33) reported that the -634G/C polymorphism does not appear to represent a risk factor for breast cancer. The inconsistent role of the $-634 \mathrm{G} / \mathrm{C}$ 
polymorphism may be due to the association between -634G/C and other unknown functional SNPs or environmental factors in the angiogenesis pathway. In addition, the variations in ethnicities, study design, tumor types and sample size demonstrated by these studies may affect the results and cause such discrepancies. Therefore, additional studies with different populations are required to confirm the association between this polymorphism and the risk of cancer.

In the present study, it was found that the $-634 \mathrm{G} / \mathrm{C}$ polymorphism is associated with the prognosis of osteosarcoma. Previous studies have reported that $-634 \mathrm{G} / \mathrm{C}$ polymorphism is associated with the clinical outcome of breast, gastric, prostate and ovarian cancers (33-36). One study investigated the association between VEGF polymorphism and the prognosis of osteosarcoma, but this previous study did not identify that the $-634 \mathrm{G} / \mathrm{C}$ polymorphism played a role in the clinical outcome of osteosarcoma (37). Additional studies are required to confirm the association between this polymorphism and osteosarcoma.

Several limitations should be considered in the present study. First, the enrolled patients and control individuals were selected from one hospital. A certain risk of selection bias may be present, as the patients and control individuals were not a random sample of patients with osteosarcoma and may not be representative of the overall situation of patients with osteosarcoma. Secondly, due to the rarity of osteosarcoma, only a small number of patients with osteosarcoma were enrolled. The relatively small sample size may limit the statistical power to identify differences between groups. Thirdly, additional factors in the angiogenesis pathway may affect the development and prognosis of osteosarcoma, and the VEGF gene polymorphism may interact with these factors. Therefore, additional large samples are required to confirm the association between VEGF gene polymorphisms and the development and prognosis of osteosarcoma.

In summary, the present study revealed that the VEGF-634G/C polymorphism is an independent factor for the development and prognosis of osteosarcoma. The VEGF-634G/C polymorphism may be used as a genetic marker for the prediction of the risk and clinical outcome of osteosarcoma.

\section{References}

1. Mirabello L, Troisi RJ and Savage SA: Osteosarcoma incidence and survival rates from 1973 to 2004: Data from the Surveillance, Epidemiology, and End Results Program. Cancer 115: $1531-1543,2009$.

2. Ottaviani $G$ and Jaffe N: The epidemiology of osteosarcoma. Cancer Treat Res 152: 3-13, 2009.

3. Picci P: Osteosarcoma (osteogenic sarcoma). Orphanet J Rare Dis 2: 6, 2007.

4. Powers M, Zhang W, Lopez-Terrada D, Czerniak BA and Lazar AJ: The molecular pathology of sarcomas. Cancer Biomark 9: 475-491, 2010.

5. Bovée JV and Hogendoorn PC: Molecular pathology of sarcomas: Concepts and clinical implications. Virchows Arch 456: 193-199, 2010.

6. de Álava E: Molecular pathology in sarcomas. Clin Transl Oncol 9: 130-144, 2007.

7. Osuna D and de Alava E: Molecular pathology of sarcomas. Rev Recent Clin Trials 4: 12-26, 2009.

8. Berger M, Muraro M, Fagioli F and Ferrari S: Osteosarcoma derived from donor stem cells carrying the Norrie's disease gene. N Engl J Med 359: 2502-2504, 2008.
9. He M, Wang Z, Zhao J, Chen Y and Wu Y: COL1A1 polymorphism is associated with risks of osteosarcoma susceptibility and death. Tumour Biol 35: 1297-1305, 2014.

10. He ML, Wu Y, Zhao JM, Wang Z and Chen YB: PIK3CA and AKT gene polymorphisms in susceptibility to osteosarcoma in a Chinese population. Asian Pac J Cancer Prev 14: 5117-5122, 2013.

11. Jia J, Tian Q, Liu Y, Shao ZW and Yang SH: Interactive effect of bisphenol A (BPA) exposure with $-22 \mathrm{G} / \mathrm{C}$ polymorphism in LOX gene on the risk of osteosarcoma. Asian Pac J Cancer Prev 14: 3805-3808, 2013.

12. Zhang SL, Mao NF, Sun JY, Shi ZC, Wang B and Sun YJ: Predictive potential of glutathione S-transferase polymorphisms for prognosis of osteosarcoma patients on chemotherapy. Asian Pac J Cancer Prev 13: 2705-2709, 2012.

13. Wang W, Wang J, Song H, Liu J, Song B and Cao X: Cytotoxic T-lymphocyte antigen- $4+49 \mathrm{G} / \mathrm{A}$ polymorphism is associated with increased risk of osteosarcoma. Genet Test Mol Biomarkers 15: 503-506, 2011.

14. Patard JJ, Pouessel D, Bensalah K and Culine S: Targeted therapy in renal cell carcinoma. World J Urol 26: 135-140, 2008

15. Motzer RJ, Hutson TE, Tomczak P, Michaelson MD, Bukowski RM, Rixe O, Oudard S, Negrier S, Szczylik C, Kim ST, et al: Sunitinib versus interferon alfa in metastatic renal-cell carcinoma. N Engl J Med 356: 115-124, 2007.

16. Watson CJ, Webb NJ, Bottomley MJ and Brenchley PE: Identification of polymorphisms within the vascular endothelial growth factor (VEGF) gene: Correlation with variation in VEGF protein production. Cytokine 12: 1232-1235, 2000.

17. Jain L, Vargo CA, Danesi R, Sissung TM, Price DK, Venzon D, Venitz J and Figg WD: The role of vascular endothelial growth factor SNPs as predictive and prognostic markers for major solid tumors. Mol Cancer Ther 8: 2496-2508, 2009.

18. Yan Y, Liang H, Li T, Guo S, Li M, Li S and Qin X: Vascular endothelial growth factor $+936 \mathrm{C} / \mathrm{T}$ polymorphism and breast cancer risk: A meta-analysis of 13 case-control studies. Tumour Biol 35: 2687-2692, 2014.

19. Martinez-Fierro ML, Garza-Veloz I, Rojas-Martinez A, Ortiz-Lopez R, Castruita-de la Rosa C, Ortiz-Castro Y, Lazalde-Ramos BP, Cervantes-Villagrana AR, Castañeda-Lopez ME, Gomez-Guerra L, et al: Positive association between vascular endothelial growth factor (VEGF) $-2578 \mathrm{C} / \mathrm{A}$ variant and prostate cancer. Cancer Biomark 13: 235-241, 2013.

20. Zhang Y, Li S, Xiao HQ, Hu ZX, Xu YC and Huang Q: Vascular endothelial growth factor gene polymorphisms and renal cell carcinoma: A systematic review and meta-analysis. Oncol Lett 6: 1068-1078, 2013.

21. Wang Z, Wen P, Luo X, Fang X, Wang Q, Ma F and Lv J: Association of the vascular endothelial growth factor (VEGF) gene single-nucleotide polymorphisms with osteosarcoma susceptibility in a Chinese population. Tumour Biol 35: 36053610,2014

22. Tie Z, Bai R, Zhai Z, Zhang G, Zhang H, Zhao Z, Zhou D and Liu W: Single nucleotide polymorphisms in VEGF gene are associated with an increased risk of osteosarcoma. Int J Clin Exp Pathol 7: 8143-8149, 2014.

23. Enneking WF, Spanier SS and Goodman MA: A system for the surgical staging of musculoskeletal sarcoma. Clin Orthop Relat Res: 106-120, 1980.

24. Salven P, Teerenhovi L and Joensuu H: A high pretreatment serum vascular endothelial growth factor concentration is associated with poor outcome in non-Hodgkin's lymphoma. Blood 90: 3167-3172, 1997.

25. Leng WD, He MN, Chen QL, Gong H, Zhang L and Zeng XT: Vascular endothelial growth factor (VEGF) gene polymorphisms and risk of head and neck cancer: A meta-analysis involving 2,444 individuals. Mol Biol Rep 40: 5987-5992, 2013.

26. Kushner EJ and Bautch VL: Building blood vessels in development and disease. Curr Opin Hematol 20: 231-236, 2013.

27. Roy H, Bhardwaj S and Ylä-Herttuala S: Biology of vascular endothelial growth factors. FEBS Lett 580: 2879-2887, 2006

28. Renner W, Kotschan S, Hoffmann C, Obermayer-Pietsch B and Pilger E: A common $936 \mathrm{C} / \mathrm{T}$ mutation in the gene for vascular endothelial growth factor is associated with vascular endothelial growth factor plasma levels. J Vasc Res 37: 443-448, 2000.

29. Koukourakis MI, Papazoglou D, Giatromanolaki A, Bougioukas G, Maltezos E and Sivridis E: VEGF gene sequence variation defines VEGF gene expression status and angiogenic activity in non-small cell lung cancer. Lung Cancer 46: 293-298, 2004. 
30. Liu H, Wang S and Huang C: VEGFA+936C/T and -634G/C polymorphisms and gastric cancer risk: A meta-analysis. Asian Pac J Cancer Prev 12: 1979-1983, 2011.

31. Zhao Z, Ba C, Wang W, Wang X, Xue R and Wu X: Vascular endothelial growth factor (VEGF) gene polymorphisms and colorectal cancer: A meta-analysis of epidemiologic studies. Genet Test Mol Biomarkers 16: 1390-1394, 2012.

32. Deng ZC, Cao C, Yu YM, Ma HY and Ye M: Vascular endothelial growth factor $-634 \mathrm{G} / \mathrm{C}$ and vascular endothelial growth factor -2578C/A polymorphisms and lung cancer risk: A case-control study and meta-analysis. Tumour Biol 35: 1805-1811, 2014.

33. Yao W, Yan R, Ma L, Wan H, Yu Y, Cheng X and Li Y: Vascular endothelial growth factor gene polymorphism $(-634 \mathrm{G} / \mathrm{C})$ and breast cancer risk. Tumour Biol 35: 7793-7798, 2014.

34. Sa-Nguanraksa D, Chuangsuwanich T, Pongpruttipan T, Kummalue T, Rojananin S, Ratanawichhitrasin A, Prasarttong-Osoth P, Chuthatisith S, Pisarnturakit P, Aeumrithaicharoenchok W, et al: Vascular endothelial growth factor $634 \mathrm{G} / \mathrm{C}$ polymorphism is associated with increased breast cancer risk and aggressiveness. Mol Med Rep 8: 1242-1250, 2013.
35. Liao WC, Lin JT, Wu CY, Huang SP, Lin MT, Wu AS, Huang YJ and Wu MS: Serum interleukin-6 level but not genotype predicts survival after resection in stages II and III gastric carcinoma. Clin Cancer Res 14: 428-434, 2008.

36. Sfar S, Saad H, Mosbah F and Chouchane L: Combined effects of the angiogenic genes polymorphisms on prostate cancer susceptibility and aggressiveness. Mol Biol Rep 36: 37-45, 2009.

37. Hefler LA, Mustea A, Könsgen D, Concin N, et al: Vascular endothelial growth factor gene polymorphisms are associated with prognosis in ovarian cancer. Clin Cancer Res 13: 898-901, 2007. 